\title{
Journal of Pediatric Neurology \&

\section{The Factors Most Important for Quality of Life in Children and Adolescents with Cerebral Palsy}

Brian Piazza*, William Hennrikus, Ryan Schell, Douglas Armstrong and Kristine Fortuna

Department of Pediatric Orthopaedics, Penn State College of Medicine, USA

*Corresponding author: Brian Piazza, Department of Pediatric Orthopaedics, Penn State College of Medicine, 30 Hope Drive Hershey, PA 17033, USA, Tel: (717) 531-7006; Fax: (717) 531-0126; E-mail: bpiazza@hmc.psu.edu

Received date: Dec 16, 2015; Accepted date: Jan 19, 2016; Published date: Jan 25, 2016

Copyright: () 2016 Piazza B, et al. This is an open-access article distributed under the terms of the Creative Commons Attribution License, which permits unrestricted use, distribution, and reproduction in any medium, provided the original author and source are credited.

\begin{abstract}
Aim: This study's purpose is to determine what themes patients with Cerebral Palsy (CP) rate most highly for importance in their quality of life. Additionally, we aim to determine and compare the parent's perception of quality of life measures for their child with CP.

Methods: Thirty one patients with CP and their guardians were administered a 50 item questionnaire.

Results: When comparing the quality of life ratings of patients with CP to parents, five measures were statistically significant. Patients thought that playing video games $(p=0.039)$, using the TV $(p=0.004)$ and how their physical disability affects their appearance in comparison to their peers $(p=0.018)$ were more important than their parents did. Parents thought their child's future financial independence $(p=0.017)$ and access to healthcare $(p=0.008)$ were more important than their adolescent children did.
\end{abstract}

Interpretation: Parents can accurately predict a few of the quality of life measures important to their child such as eating and drinking independently and going to school. However, disparities exist in many psycho-social domains. A better understanding of the importance of quality of life themes for patients with CP is important because it helps to direct care that can both take advantage of and improve what our patients feel is most important.

Keywords: Cerebral palsy; Quality of life; Adolescent

\section{Introduction}

There is no cure for cerebral palsy (CP) and the residual brain defect remains static. Therefore, patients with $\mathrm{CP}$ often have disabilities that affect their quality of life (QOL) for their entire life. Previous studies using non-validated surveys have suggested that adults with CP have identified 'education and communication' over themes such as 'gait and ambulation' as more important for their quality of life [1,2]. Studies have also shown that young adults with cerebral palsy (CP) lag behind their peers in their development and transition to adulthood [3]. In particular, patients lag behind in forming relationships and involvement with peers [4].

Patients with CP have been shown to have lower quality of life (QOL) scores than their peers [5]. Although severity of disability has a large impact on QOL and the transition to adulthood [6], disability is not always linked to QOL, especially in the psychosocial domains $[7,8]$. Parenting style has been shown to be a significant factor in QOL for patients with $\mathrm{CP}$ and is the only known factor that impacts the psychosocial domains of the Child Health Questionnaire (CHQ) [9]. Parenting style is an important part of the patient's transition to adulthood and patients with parents who are accepting of disability limitations and foster autonomy have been shown to have higher QOL scores [10].

Previous studies have also shown that although parents can accurately predict their child's QOL; there are disparities particularly in the psychosocial domains $[11,12]$. Although qualitative studies have been performed to develop QOL tests 7 no quantitative studies have been used to identify particular areas of importance for QOL. The purpose of this study is to determine what themes child and adolescent patients with $\mathrm{CP}$ rate most highly for importance in their quality of life. In addition, we also aim to determine and compare the parent's perception of quality of life measures for their child with CP.

\section{Materials and Methods}

The study was approved by the institution's Institutional Review Board. Consent was obtained from both patients and their parents. Thirty one adolescent and child patients with $\mathrm{CP}$ were administered a fifty item questionnaire under the supervision of a research assistant. The sample size was derived from the population of patients meeting the inclusion criteria at a large regional Children's Hospital in the United States. Twenty eight children unable to complete the questionnaire were not included in the study because of either cognitive or motor access problems. The decision to exclude patients from the study was decided by the parents, if they felt their child would be unable to understand or complete the questionairre. Four children felt to be capable of completing the questionnaire by the physician were excluded at the requests of their parents. Three of these families cited not having time to participate as the reason for exclusion. The questionnaire was formed via analysis of current validated quality of life surveys including the Pediatric Quality of Life Inventory (PedsQL) [13], Child Health Questionnaire (CHQ) [14], the Pediatric Outcomes Data Collections Instrument (PODCI) [15], the Rotterdam Transition Profile (RTP) [3] and the CP-QOL questionnaires [16], a review of the 
Page 2 of 4

current literature and expert opinion. Each question was scaled from 1 to 9 in importance to the patient's quality of life. The parents were also asked to independently complete an identical questionnaire about their child. Patients and guardians were separated into different rooms and filled out the surveys independently. Statistical analysis between the ratings by the patients and their parents were compared with the Wilcoxon rank-sum test. $(\mathrm{P}<0.05$ was significant). In addition, the individual items of the questionnaire were sub-grouped into four domains: activities of daily life, advanced activities, psycho-social and access to resources.

\section{Results}

Thirty one patients and thirty seven parents were included in the study. The average age of the patients was fourteen years (range 9-17). Sixteen were male and fifteen were female. Fourteen patients had hemiplegic $\mathrm{CP}$, eleven were diplegic, five were quadriplegic and one was monoplegic. The patients were also classified by their Gross Motor Function Classification Score (GMFCS); fourteen were level I, ten were level II, two were level III, two was level IV and three were level V. Thirty seven parents --fourteen fathers and twenty three mothers also filled out the questionnaire. The average age of the parents was forty four years (range 28-58). Table 1 shows the demographics of the patients and their parents.

\begin{tabular}{|c|c|c|}
\hline \multicolumn{3}{|c|}{ Table I: Demographic characteristics } \\
\hline \multirow[t]{2}{*}{ Patient Age } & Range & $9-17$ yrs \\
\hline & Mean & $14 \mathrm{yrs}$ \\
\hline \multirow[t]{2}{*}{ Sex } & Male & $16(51.61 \%)$ \\
\hline & Female & $15(48.39 \%)$ \\
\hline \multirow[t]{4}{*}{ Diagnosis } & Monoplegia & $1(3.23 \%)$ \\
\hline & Diplegia & $11(35.48 \%)$ \\
\hline & Hemiplegia & $14(45.16 \%)$ \\
\hline & Quadriplegia & $5(16.13 \%)$ \\
\hline \multirow[t]{5}{*}{ GMFCS } & I & 14 \\
\hline & II & 10 \\
\hline & III & 2 \\
\hline & IV & 2 \\
\hline & V & 3 \\
\hline
\end{tabular}

\begin{tabular}{|l|l|l|}
\hline \multirow{2}{*}{ Parent Age } & Range & $28-58 \mathrm{yrs}$ \\
\cline { 2 - 3 } & Mean & $44 \mathrm{yrs}$ \\
\hline Parent Sex & Male & $14(37.84 \%)$ \\
\cline { 2 - 3 } & Female & $23(62.16 \%)$ \\
\hline
\end{tabular}

Table I: Demographic characteristics.

The top five quality of life measures as rated by the patients were: (1) eating and drinking independently, (2) attending school (3) using a computer, (4) forming relationships with their peers, (5)walking. The top 5 quality of life measures as rated by the parents were: (1) eating and drinking independently, (2) attending school, (3) using the toilet independently, (4) access to therapy, (5) access to health care.

When comparing the quality of life ratings of patients with CP to parents, five measures were statistically significant, seen in Table 3. Patients thought that playing video games $(p=0.039)$, using the TV $(\mathrm{p}=0.004)$ and how their physical disability affects their appearance in comparison to their peers $(\mathrm{p}=0.018)$ were more important than their parents did. Parents thought their child's future financial independence $(p=0.017)$ and access to healthcare $(p=0.008)$ were more important than their children did.

Patients were also grouped according to their GMFCS score into Ambulators (GMFCS scores I, II and II) and non-ambulators (GMFCS IV and V). Comparing the subgroup of quadriplegic patients to diplegic and hemiplegic patients, the importance of access to wheelchairs, ramps, special seating and standing bars at home $(\mathrm{P}=0.005, \mathrm{p}=0.006, \mathrm{p}=0.003, \mathrm{p}=0.006)$ and school $(\mathrm{P}=0.005, \mathrm{p}=0.040$, $\mathrm{p}=0.011, \mathrm{p}=0.005)$ were all significant. In contrast, patients with diplegic and hemiplegic CP found dressing oneself $(\mathrm{p}=0.046)$, using the toilet independently $(\mathrm{p}=0.031)$ and arranging their own transportation (car ride, bus ride, etc.) $(\mathrm{p}=0.026)$ to more important than their peers with quadriplegic CP. When comparing the parents of quadriplegic patients to the parents of diplegic and hemiplegic patients, participation in after school activities $(\mathrm{p}=0.04)$, access to wheelchairs, ramps and special seating at home $(\mathrm{P}=0.033, \mathrm{p}=0.011$, $\mathrm{p}=0.018)$ and at school $(\mathrm{P}=0.032, \mathrm{p}=0.037, \mathrm{p}=0.037)$ were significant. Parents of less disabled hemiplegic and diplegic patients found activities of daily life more important for their children than parents of quadriplegic patients, such as, dressing themselves $(\mathrm{p}=0.002)$, tying their own shoe laces $(\mathrm{p}=0.019)$ and brushing their own teeth $(\mathrm{p}=0.007)$.

\begin{tabular}{|l|l|l|l|}
\hline & Patient mean & Parent Mean & p \\
\hline Using a TV Remote: & 7.30 & 6.11 & $0.039^{*}$ \\
\hline Playing Video games: & 7.07 & 4.92 & $0.004^{*}$ \\
\hline Financial independence: & 6.03 & 7.69 & $0.018^{*}$ \\
\hline $\begin{array}{l}\text { How your physical disability affects } \\
\text { your appearance in comparison to } \\
\text { other children: }\end{array}$ & 6.76 & 4.89 & $0.017^{*}$ \\
\hline Access to healthcare: & 6.28 & 8.11 & $0.008^{*}$ \\
\hline
\end{tabular}


Table 3: Patient vs. parent comparison of the importance of QOL factors.

Female parents were also compared to their male counterparts. Female parents found several QOL factors more important including: interactions with other children at school $(\mathrm{p}=0.026)$, forming new friendships with other children $(\mathrm{p}=0.027)$, activities with other children outside of school $(\mathrm{p}=0.039)$, interactions with other adults $(p=0.048)$ and fostering their child's independence $(p=0.024)$. Male parents found no QOL factors significantly more important than female parents.
When the QOL factors are grouped into the meta-categories of activities of daily life, psychosocial well-being, advanced daily activities and access to resources, parents are shown to hold advanced activities $(\mathrm{p}=0.0002)$ and access to resources $(\mathrm{p}=0.0183)$ as more important than their children as in Table 2.

\begin{tabular}{|l|l|}
\hline Meta-categories & P-value \\
\hline Activities of daily life & 0.998 \\
\hline Psychosocial & 0.1782 \\
\hline Advanced activities & $0.0002^{*}$ \\
\hline Access to resources & $0.0183^{*}$ \\
\hline${ }^{*}$ Indicates statistic significance & \\
\hline
\end{tabular}

Table 2: Patient vs. Parent comparison of the importance of QOL meta-categories.

\section{Discussion}

We found that parents can accurately predict a few of the quality of life measures important to their child such as eating and drinking independently and going to school. However, disparities exist between the patient's and the parent's perception of important quality of life measures in many psycho social domains. With parenting style being the first specific factor shown to implicate psychosocial aspects of QOL in children with CP [9] it is important to understand that parents and patients do not value all QOL factors the same.

When examining our results, we see that patients with $\mathrm{CP}$ find that how their disease affects their appearance, watching TV and playing video games are more important in their daily life than their parents. It is easy to excuse this as normal adolescent behavior or may be related to cognitive level, but it is also important to remember that with physical limitations, patients with CP have limited opportunities for extra-curricular activities. This is especially true when looking specifically at activities that their peers are involved in. Rather than ignore this as true for all children, it is important to look how their interest in video games can be turned into a positive. It has been shown that active video games, i.e. motion capture $\left(\mathrm{Wii}^{\odot}, \mathrm{Xbox} \mathrm{Kinect}^{\odot}\right)$, can be used to increase physical activity levels and function as rehabilitation improving postural control, functional mobility and visual-perceptual processing [17-19]. This is especially important since it has been shown that adolescents with CP have lower activity levels than their non-disabled peers [20].

Overall when looking at the meta-categories parents thought that advanced activities and access to healthcare, special services and tools in the community were more important than what their children thought. One author has shown that as adolescents with CP progress to adult age they often have unmet medical needs due to the fragmentation of services [2]. Pediatric healthcare for patients with disabilities has been organized for efficient multidisciplinary care at major facilities with social workers, physical therapist, orthopaedist, neurologists and general pediatricians, who are used to caring for patients with $\mathrm{CP}$ in a single clinic. The patient's disinterest in planning for the future compared to their parents concern could be attributed to being an adolescent. Many patients with $\mathrm{CP}$ will live independently after adolescence. Involving these patients in their healthcare choices early is important because it will educate the teenage patient with $\mathrm{CP}$ so they may better navigate the complex and segmented adult healthcare setting.

This paper provides a snapshot view of how respondents feel about their disability at one time point and is not a study of how their views change over time. The aim of the study was to determine the relationship of patients' and parents' perception. Improvements to this study could include validation of our questionnaire and enrolling more participants such that comparison between child and adolescent patients could be performed. Limitations of the study include the exclusion of 28 children and adolescents with cerebral palsy. The most common reason for exclusion was inability to complete the questionnaire due to cognitive delay. Due to this, we recognize that this study is representative of a population of cerebral palsy patients with higher function and excludes more disabled individuals. We also recognize that patients felt capable of completing the questionnaire but excluded by their parents may represent a revealing subset of data that could potentially differ from families that had an interest in participating in the study.

A better understanding of the importance of quality of life themes for patients with $\mathrm{CP}$ is important because it helps to direct care that can both take advantage of and improve what our patients feel as most important. In addition, this knowledge can increase our ability to communicate effectively with our patients, as well as, our colleagues in other disciplines. A clearer understanding of the needs of our patients will help physicians balance the priorities of our patients versus their 
Citation: Piazza B, Hennrikus W, Schell R, Armstrong D, Fortuna K (2016) The Factors Most Important for Quality of Life in Children and Adolescents with Cerebral Palsy. J Pediatr Neurol Med 1: 1000102. doi:10.4172/2472-100x.1000102

Page 4 of 4

parents and potentially improve our awareness and responsibility to our patients with CP. We hope the current study stimulates more research to understand how patients with CP rank QOL factors. So, patient-centered care may therefore be better directed and patientphysician communication may be strengthened.

\section{References}

1. Bleck EE (1984) Where have all the CP children gone?--the needs of adults. Dev Med Child Neurol 26: 674-676.

2. O'Neill DL, Harris SR (1982) Developing goals and objectives for handicapped children. Phys Ther 62: 295-298.

3. Donkervoort M, Wiegerink DJ, van Meeteren J, Stam HJ, Roebroeck ME; Transition Research Group South West Netherlands (2009) Transition to adulthood: validation of the Rotterdam Transition Profile for young adults with cerebral palsy and normal intelligence. Dev Med Child Neurol 51: 53-62

4. Wiegerink DJ, Roebroeck ME, van der Slot WM, Stam HJ, CohenKettenis PT; South West Netherlands Transition Research Group (2010) Importance of peers and dating in the development of romantic relationships and sexual activity of young adults with cerebral palsy. Dev Med Child Neurol 52: 576-582.

5. Roebroeck ME, Jahnsen R, Carona C, Kent RM, Chamberlain MA (2009) Adult outcomes and lifespan issues for people with childhood-onset physical disability. Dev Med Child Neurol 51: 670-678.

6. Videler AJ, Beelen A, van Schaik IN, de Visser M, Nollet F (2009) Limited upper limb functioning has impact on restrictions in participation and autonomy of patients with hereditary motor and sensory neuropathy 1a. J Rehabil Med 41: 746-750.

7. Davis E, Shelly A, Waters E, Mackinnon A, Reddihough D, et al. (2009) Quality of life of adolescents with cerebral palsy: perspectives of adolescents and parents. Dev Med Child Neurol 51: 193-199.

8. Vargus-Adams J (2009) Quality of Life for adolescents with cerebral palsy: perspectives of adolescents and parents. Dev Med Child Neurol 51:168-172.

9. Aran A, Shalev RS, Biran G, Gross-Tsur V (2007) Parenting style impacts on quality of life in children with cerebral palsy. J Pediatr 151: 56-60, 60.
10. Rapin I (2007) Children with cerebral palsy assess their parents' influence on the quality of their lives: implications for intervention. J Pediatr 151: 7-9.

11. Majnemer A, Shevell M, Law M, Poulin C, Rosenbaum P (2008) Reliability in the ratings of quality of life between parents and their children of school age with cerebral palsy. Qual Life Res 17: 1163-1171.

12. Waters E, Davis E, Ronen GM, Rosenbaum P, Livingston M, et al. (2009) Quality of life instruments for children and adolescents with neurodisabilities: how to choose the appropriate instrument. Dev Med Child Neurol 51: 660-669.

13. Varni JW, Burwinkle TM, Berrin SJ, Sherman SA, Artavia K, et al. (2006) The PedsQL in pediatric cerebral palsy: reliability, validity, and sensitivity of the Generic Core Scales and Cerebral Palsy Module. Dev Med Child Neurol 48: 442-449.

14. Landgraf JM, Abetz L, Ware JA (1996) The CHQ User's Manual. 1st edn. Boston: The Health Institute, New England Medicine Centre.

15. Daltroy LH, Liang MH, Fossel AH, Goldberg MJ (1998). The POSNA pediatric musculoskletal functional health questionnaire: report on reliability, validity and sensitivity to change. J Pediatr Orthop 18: 561-571.

16. Waters E, Davis E, Mackinnon A, Boyd R, Graham HK, et al. (2007) Psychometric properties of the quality of life questionnaire for children with CP. Dev Med Child Neurol 49: 49-55.

17. Jannink MJ, van der Wilden GJ, Navis DW, Visser G, Gussinklo J, et al. (2008) A low-cost video game applied for training of upper extremity function in children with cerebral palsy: a pilot study. Cyberpsychol Behav 11: 27-32.

18. Deutsch JE, Borbely M, Filler J, Huhn K, Guarrera-Bowlby P (2008) Use of a low-cost, commercially available gaming console (Wii) for rehabilitation of an adolescent with cerebral palsy. Phys Ther 88: 1196-1207.

19. Hurkmans HL, van den Berg-Emons RJ, Stam HJ (2010) Energy expenditure in adults with cerebral palsy playing Wii Sports. Arch Phys Med Rehabil 91: 1577-1581.

20. Maher CA, Williams MT, Olds T, Lane AE (2007) Physical and sedentary activity in adolescents with cerebral palsy. Dev Med Child Neurol 49: 450-457. 